\title{
Eudicot nutshells: Cell-wall composition and biofuel feedstock potential
}

\author{
Leta Landucci, Rebecca A. Smith, Sarah Liu, Steven D. Karlen, John Ralph*
}

Department of Biochemistry and Great Lakes Bioenergy Research Center, University of

Wisconsin-Madison, Madison, WI, USA

Included in the SI package is a key for the location of cross-correlation peaks in the 4:1 DMSO$\mathrm{d}_{6} /$ pyridine- $\mathrm{d}_{5}$ solvent system. The file is aptly named "Key for annotations.xlsx" and also includes the abbreviation scheme used in the manuscript and a description of the lignin subunit, lignin linkage, sugar, amino acid, or chemical. The annotated raw 2D HSQC NMR data sets for the enzymatically isolated nutshell lignin samples are provided in the Bruker Topspin format. As such we have retained the Bruker folder structure and labeled the sample folders:

LLa23-EL-Almond Nutshell

LLa23-EL-Brazil Nut Nutshell

LLa23-EL-Hazelnut Nutshell

LLa23-EL-Hickory Nutshell

LLa23-EL-Macademia Nutshell

LLa23-EL-Pecan Nutshell

LLa23-EL-Walnut Nutshell

LLa23-EL-Mango Nutshell

LLa23-EL-Pistachio Nutshell 